\title{
Changes of hepatic biochemical parameters and proteomics in broilers with cold-induced ascites
}

\author{
Yongwei Wang, Yuming Guo ${ }^{*}$, Dong Ning, Yunzhi Peng, Hong Cai, Jianzhuang Tan, Ying Yang and Dan Liu
}

\begin{abstract}
Ascites syndrome is still a problem for chicken industry in various parts of the world. Despite the intensive investigations of this syndrome for many years, its pathogenesis remains unclear. The objective of this study was to analyze the difference in hepatic proteomics between ascites and healthy broilers by two-dimensional electrophoresis (2-DE) and matrix-assisted laser desorption/ionization-time of flight mass spectrometry (MALDI-TOF-MS). Changes of biochemical parameters of liver and blood were also determined. The results indicated that red blood cell counts (RBC), hematocrit (HCT) and haemoglobin (HGB) of ascites broilers were significantly greater than healthy broilers. Hepatic malondialdehyde (MDA) level of ascites broilers was significantly increased, and the activity of total superoxide dismutase (T-SOD) was significantly decreased. Hepatic lactic acid (LD) level of ascitic broilers were significantly lower than healthy ones. Serum glucose and cholesterol level of ascites broilers were significantly increased, and serum globulin level was significantly decreased in ascites broilers. There was no significant difference in triglyceride (TG) and blood urea nitrogen (BUN) level. The activity of liver hexokinase (HK) and succinodehydrogenase $(\mathrm{SDH})$ in ascites broilers was significantly decreased, and there was no significant difference in the activity of liver pyruvate kinase (PK) and $\mathrm{Na}^{+}-\mathrm{K}^{+}$-ATPase. The hepatic proteomics analysis showed that 18 proteins expression difference were identified between ascites and healthy broilers. These proteins were mainly involved in:

1) cytoskeleton; 2) glucose, lipids and amino acid metabolism; 3) cell secretion; 4) cell apoptosis; 5) signal transduction; 6) immune and inflammatory response; and 7) cellular redox homeostasis. Mitochondrial isoform phosphoenolpyruvate carboxykinase (M-PEPCK) mainly participates in gluconeogenesis of chicken liver. In conclusion, liver oxidative damage was significantly aggravated, but antioxidant capacity was decreased in cold-induced ascites broilers. Serum glucose level was significantly increased, with liver M-PEPCK expression higher in ascites broilers, which implied that some potential regulatory reagents may reduce ascites susceptibility and mortality under cold temperature by increasing liver gluconeogenesis level.
\end{abstract}

Keywords: Ascites, Broilers, Biochemical parameters, Proteomics analysis

\section{Introduction}

It is reported that $5 \%$ of broilers and $20 \%$ of roaster birds die of ascites, the economic loss due to ascites was significant [1]. Despite intensive investigations of the syndrome for decades, the pathogenesis and underlying mechanisms of ascites is yet to be understood [2-6]. It has been shown that histologic lesions [7], significant reduction of hemoglobin content respective to red blood cell count $[8,9]$, decreased production of vessel dilating active substances [10], abnormal metabolism of corticosteroids and triiodothyronine [9], and down-regulation of

\footnotetext{
* Correspondence: guoyum@cau.edu.cn

State Key Lab of Animal Nutrition, College of Animal Science and

Technology, China Agricultural University, Beijing 100193, PR China
}

lung inflammatory chemokine genes [11], are involved in the occurrence of ascites.

The profound changes of liver glucose and lipids metabolism are associated with the metabolic abnormalities (such as obesity and diabetes), and differentially expressed proteins are responsible for the metabolic disorder [12,13]. Cisar et al. (2005) studied the differentially expressed proteins in myocardial mitochondria matrix between ascites-resistant and ascites-susceptible line broilers with and without ascites using 2-DE, the results indicated that mitochondria of ascites broilers may inappropriately respond to hypoxia [14]. However, hepatic differentially expressed proteins in ascites broilers were not yet identified.

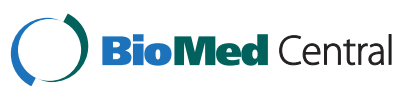


Cold temperature can increase ascites susceptibility by increasing metabolic oxygen requirements [15]. However, there is little information about the changes of physiological parameters such as fasting blood glucose, serum protein, triglyceride, liver antioxidative capacity and metabolic enzymes activities between ascites and healthy broilers under a cold environment [16-18].

The objective of this study was to investigate the changes of hepatic proteomics profile, and changes of biochemical parameters of blood and liver tissue between ascites and healthy broilers under a low temperature environment.

\section{Materials and methods \\ Experimental design}

A total of 196 day-old male broilers (Ross-308) were randomly assigned to fourteen replicate cages $(2.4 \times$ $0.6 \times 0.6 \mathrm{~m})$ of 14 birds each. The temperature in the house was $35^{\circ} \mathrm{C}$ during the first week, and was lowered by $1^{\circ} \mathrm{C}$ every other day till $30^{\circ} \mathrm{C}$ was reached on day 10 . From day 11 to the end of experiment (42 days), all birds were exposed to a temperature regime of $17^{\circ} \mathrm{C}$ during the day and $14^{\circ} \mathrm{C}$ at night in order to increase ascites susceptibility. Diets (Table 1) were formulated to meet or exceed recommended requirements for all nutrients [19] and were pelleted. Birds had free access to feed and water, with $23 \mathrm{~h}$ fluorescent illumination per day throughout the experimental period. Birds were vaccinated with newcastle disease-infectious bronchitis (NDIB) vaccine at 7 and 21 days age, and infectious bursal disease (IBD) vaccine at 14 and 28 days age. The study protocol was approved and conducted in accordance with the Animal Ethics Committee guidelines of China Agricultural University.

\section{Sampling and measuement \\ Blood biochemical parameters and organ index}

On days 39 (the age at which a peak in the syndrome was demonstrated previously [20], 80 birds were selected and weighted after $8 \mathrm{~h}$ of feed deprivation. Whole blood samples were collected by venipuncture into EDTA- $K_{3}$ anticoagulation tubes for the measurement of $\mathrm{RBC}$, HCT and HGB (Sysmex KX-21 N Automatic blood analyzer, Kobe, Japan). Another set of blood samples were immediately collected into non-anticoagulant tubes to obtain serum for the determination of glucose, total protein, globulin, triglyceride, cholesterol (Unicel DXC 800, Beckman Coulter, California, America). Blood urea nitrogen (BUN) was measured using commercially available colorimetric diagnostic kits as manufacturer's instructions (Nanjing Jiancheng Bioengineering Institute, Nanjing, China).

Then the birds were killed by jugular bleeding. Liver, lung, and heart were separated to calculate liver index,
Table 1 Composition of experimental diets

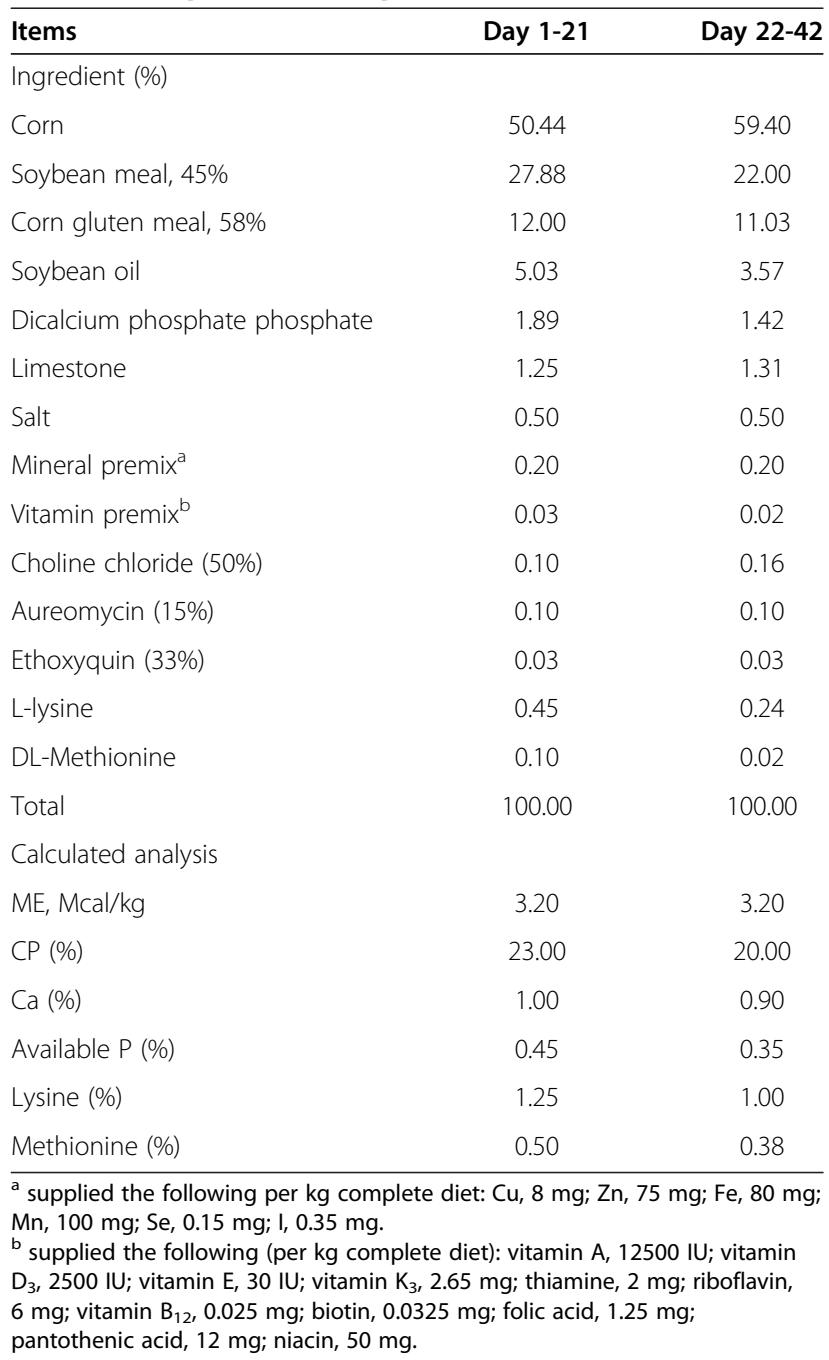

lung index, and heart index, respectively. Weights of right ventricle (RV) and total ventricle (TV) were recorded to calculate the ascites heart index (AHI). AHI was calculated as $(\mathrm{RV} / \mathrm{TV}) \times 100[21]$.

\section{Hepatic biochemical parameters}

According to the following selection criteria, liver tissue of eight ascites and healthy broilers were collected for the determination of MDA and LD level, and the activity of T-SOD, HK, SDH, PK and $\mathrm{Na}^{+}-\mathrm{K}^{+}$-ATPase. Liver tissues were minced and homogenized $(10 \%, \mathrm{wt} / \mathrm{vol})$ in physiological saline water at $4^{\circ} \mathrm{C}$, then centrifuged at $3,500 \mathrm{~g}$ for $15 \mathrm{~min}$ at $4^{\circ} \mathrm{C}$. The supernatant was collected for the determination of biochemical parameters. MDA level was determined with the method of thibabituric acid (cat ${ }^{\#}$ : A003-1). The activity of T-SOD (cat ${ }^{\#}$ : A001-1), HK (cat ${ }^{\#}$ : A077), SDH (cat ${ }^{\#}:$ A022), PK (cat ${ }^{\#}:$ A076) and $\mathrm{Na}^{+}-\mathrm{K}^{+}$-ATPase (cat ${ }^{\#}:$ A016-2), and the level of liver LD (cat ${ }^{\#}$ : A019-2) were measured using commercially 
available colorimetric diagnostic kits (Nanjing Jiancheng Bioengineering Institute, Nanjing, China) [22]. The protein content of liver tissue was measured by Coomassie Brilliant Blue G-250 reagent with bovine serum albumin as a standard.

The selection criteria was based on the following three aspects: (1) $\mathrm{HCT}<0.36$, healthy; $\mathrm{HCT} \geq 0.36$, ascites; (2) $\mathrm{AHI}<0.28$, healthy; $\mathrm{AHI} \geq 0.28$, ascites; (3) Having effusion in abdominal cavity and pericardium, ascites, no effusion, healthy.

\section{Hepatic proteomic analysis}

Another set of liver tissue were put in tubes, then snap frozen in liquid $\mathrm{N}_{2}$ and stored at $-80^{\circ} \mathrm{C}$. Based on the selection criteria mentioned above, liver tissue of four ascites and four healthy broilers were selected for the analysis of liver proteomics profile.

\section{Protein sample preparation}

Liver tissues were homogenized in a lysis buffer consisting of $40 \mathrm{mM}$ Tris, $7 \mathrm{M}$ Urea, $2 \mathrm{M}$ Thiourea, $4 \%$ CHAPS, 1\% Dithiothreitol (DTT), 1 mM EDTA-2Na, using a glass homogenization vessel in an ice bath. Tissues were ruptured using an ultrasonic cell disruptor at $0^{\circ} \mathrm{C}$ for $10 \mathrm{~min}$ with 2 -s on and 8-s off cycles. Then the lysed cell suspension was kept at $4^{\circ} \mathrm{C}$ for $2 \mathrm{~h}$ to solubilize proteins. Subsequently, the homogenate was centrifuged at $4^{\circ} \mathrm{C}$ and $12,000 \mathrm{~g}$ for $5 \mathrm{~min}$, finally the supernatant fluid was collected. Protein concentration for each of the final supernatants was determined by Bradford assay using bovine serum albumin as the standard. Protein extracts were stored in aliquots $(1.5 \mathrm{mg} / \mathrm{mL})$ at $-80^{\circ} \mathrm{C}$.

\section{Two dimensional electrophoresis}

This study consists of two groups with four replicates, so a total 8 gels were run for the 2-DE, using commercial IPG strips (pH 3-10 NL, $24 \mathrm{~cm}$, GE Healthcare, Piscataway, NJ) for isoelectric focusing electrophoresis (IEF) and then standard vertical SDS-PAGE (13\%) for second dimensional electrophoresis. Briefly, $1.5 \mathrm{mg}$ protein sample was loaded onto IPG drystrips using the in-gel sample rehydration technique, according to manufacturer's instructions. After rehydration for $12 \mathrm{~h}$, the first-dimensional IEF was carried out at $20^{\circ} \mathrm{C}$ for 100,000 Vh in the Ettan IPGphorII IEF system (GE Healthcare, Piscataway, NJ) for $24 \mathrm{~h}$. Sequentially, IPG strips were equilibrated for $15 \mathrm{~min}$ in $8 \mathrm{~mL}$ of equilibration buffer-1 (0.6 M urea, 2\% DTT, 30\% glycerol, and $50 \mathrm{mM}$ Tris-Cl, 2\% DTT, 0.07 M SDS, trace bromophenol blue, $\mathrm{pH} 8.8$ ) and then in $8 \mathrm{~mL}$ of equilibration buffer-2 $(0.6 \mathrm{M}$ urea, $0.1 \mathrm{M}$ iodoacetamide, $30 \%$ glycerol, and $50 \mathrm{mM}$ Tris- $\mathrm{Cl}$, 2\% DTT, 0.07 M SDS, trace bromophenol blue, pH 8.8) for $15 \mathrm{~min}$. The second dimensional electrophoresis was carried out on an Ettan DALTsix system (GE Healthcare) at $20^{\circ} \mathrm{C}$ for $7 \mathrm{~h}(4 \mathrm{w} / \mathrm{gel})$. Then the gels were stained with colloidal Coomassie Brilliant Blue R-250 (Amresco, Inc., Solon, $\mathrm{OH}$ ).

\section{Image analysis}

The gel images were obtained using an UMAX Imagescanner (Model Powerlook 2100XL, UMAX Technologies, Atlanta, America) and image analysis was performed using Imagemaster Platinum Version 7.0 software (GE Healthcare). After normalizing the quantity of each spot by total valid spot intensity, differentially expressed protein spot with the point value (the relative expression volume ratio) over 2.0-fold were selected and subjected to identification by mass spectrometry (MS).

\section{In-gel digestion}

Protein spots were manually obtained and destained with $100 \mu \mathrm{L}$ destaining solution (acetonitrile $(\mathrm{ACN}): 100 \mathrm{mM}$ ammonium bicarbonate $=3: 7$ ) for $1 \mathrm{~h}$, then dehydrated with $100 \mu \mathrm{L} \mathrm{ACN}$ for $15 \mathrm{~min}$. The protein samples were completely dried by vacuum centrifugation for $5 \mathrm{~min}$, and subsequently digested with $10 \mu \mathrm{L}$ of Trypsin (Amresco, Inc., Solon, OH) in $100 \mathrm{mM}$ ammonium bicarbonate at $4^{\circ} \mathrm{C}$ for $45 \mathrm{~min}$, and incubated at $37^{\circ} \mathrm{C}$ for $16 \mathrm{~h}$. The resulting peptides were subjected to sequential extraction with $70 \% \mathrm{ACN}$ and $0.1 \%$ trifluoroacetic acid (TFA) for $30 \mathrm{~min}\left(3\right.$ times at $37^{\circ} \mathrm{C}$ ), then the three retain solutions were collected together and dried until 5-6 $\mu \mathrm{L}$ left with a vacuum centrifugation (Labconco).

\section{Protein identification by MS and database queries}

Protein identification was carried out on a Matrix Assisted Laser Desorption Ionization-Time of Flight MS (MALDI-TOF-MS) (Autoflex II, Bruker, Germany). MS fingerprinting data were performed by search engine Mascot (http://www.matrixscience.com), and Bony Vertebrates taxonomy against the NCBInr database. Search parameters include: (1) trypsin, as the enzyme of protein digestion; (2) $\mathrm{MH}^{+}$and monoisotopic, as mass value; (3) unrestricted, as peptide mass; (4) $\pm 0.3 \mathrm{Da}$, as peptide mass tolerance; (5) carbamidomethyl (C), as fixed modifications; oxidation (M), as variable modifications; and (6) 1 , as maximum missed cleavages.

\section{Statistical analysis}

The biochemical parameters data were presented as Mean. The statistical analysis was performed with SPSS 16.0 software for Windows [23]. Independent sample $T$-test was used and differences were considered statistically significant at $P \leq 0.05$. 
Table 2 Changes of body weight and organ index between ascites and healthy broilers $(n=8)$

\begin{tabular}{lccccc}
\hline Items & BW $\mathbf{( k g )}$ & LI & LUI & HI & AHI \\
\hline Healthy & $2.14^{*}$ & 2.62 & 0.24 & 0.49 & 22.2 \\
Ascites & 1.65 & $3.08^{*}$ & 0.25 & $0.60^{*}$ & $29.1^{*}$ \\
SEM & 0.09 & 0.09 & 0.01 & 0.02 & 1.45 \\
p-value & 0.003 & 0.006 & NS & 0.003 & 0.009 \\
\hline
\end{tabular}

BW: Body weight, LI: Liver index, LUI: Lung index, HI: Heart index, AHI: Ascites heart index. ${ }^{*} \mathrm{P}<0.05$.

\section{Results}

Differences of body weight and organ index between ascites and healthy broilers

As shown in Table 2, body weight of ascites broiler was significantly lower than healthy broilers, and liver index, heart index and AHI of ascites broilers were significantly increased, but there was no difference in lung index between ascites and healthy broilers.

\section{Changes of blood biochemical parameters between ascites and healthy broilers}

The data of blood biochemical parameters were shown in Table 3. RBC and HCT of ascites broilers were significantly greater than healthy broilers. Serum glucose, total cholesterol level of ascites broilers was significantly increased, and serum globulin level was significantly decreased, but there was no significant difference in triglyceride and BUN level.

\section{Changes of liver biochemical parameters between ascites and healthy broilers}

Liver MDA level of ascites broilers was significantly increased, and T-SOD activity was significantly lower than in healthy broilers. The activity of liver HK, SDH in ascites broilers was significantly decreased, and there was no significant difference in the activity of liver PK and $\mathrm{Na}^{+}-\mathrm{K}^{+}$-ATPase. Liver LD level of ascitic broilers were significantly lower than healthy ones (Table 4).

\section{Changes of liver proteomics profiles between ascites and healthy broilers}

The results of liver proteomics analysis indicated that 18 proteins expression difference were identified between ascites and healthy broilers (Figure 1), including keratin, annexin, chicken M-PEPCK chain A, dihydropteridine reductase (DHPR), N-ethylmaleimide-sensitive factor (NSF), translationally-controlled tumor protein homolog (TCTP), ring finger protein 170, Rho GDP dissociation inhibitor alpha (GDI- $\alpha)$, ryncolin-1, natural killer cell enhancing factor isoform 4 (NKEF), glia maturation factor beta (GMF), neutrophil cytosol factor 2 variant (NCF) and two unnamed proteins (Table 5). Chicken MPEPCK was mainly involved in liver gluconeogenesis (Figure 2 and Figure 3). The result of the current study revealed that the expression of liver M-PEPCK chain A in ascites broilers was higher than in healthy broilers (Table 6).

\section{Discussion}

\section{Organs index and blood parameters}

The ascites syndrome in broilers is attributed to higher metabolic burdening, so one of the pathogenesis of the syndrome is metabolic hypoxia or low efficiency in oxygen utilization [2]. In the case of hypoxia, broilers have difficulties in fulfilling tissue demands for oxygen, and the birds exhibit the decreased blood saturation and increased production of RBC (partially immature) with decreased hemoglobin content relative to red blood cells, so the decrease in hemoglobin might have contributed to enhanced development of hypoxemia and aggravation of ascites [9,24]. Luger et al. (2003) found RBC and HCT were significantly increased, and with no significant change in plasma volume in ascites chickens at wks 5, which was consistent with the current study. Besides, continually increased corticosterone level might be an inducer of erythropoiesis proliferation and differentiation arrest in ascites broilers [9]. Although increased haematrocrit values (and presumably increased haemoglobin) should be positive to alleviate hypoxaemia, birds dying of ascites all showed high haematocrits, which increased blood viscosity and augmented the inability of the failing right ventricle to pump blood through vasconstricted pulmonary blood vessels $[8,25]$. The liver and heart are the important organs to consume oxygen. Many studies take AHI $>0.27-0.30$ as an indicator of ascites occurrence, with right ventricular hypertrophy and

Table 3 Changes of blood biochemical parameters between ascites and healthy broilers $(n=8)$

\begin{tabular}{|c|c|c|c|c|c|c|c|c|c|}
\hline Items & $\frac{\mathrm{RBC}}{10^{12} / \mathrm{L}}$ & HCT & $\frac{H G B}{g / L}$ & $\frac{\mathrm{GLU}}{\mathrm{mmol} / \mathrm{L}}$ & $\frac{\mathrm{TG}}{\mathrm{mmol} / \mathrm{L}}$ & $\frac{\mathrm{CHO}}{\mathrm{mmol} / \mathrm{L}}$ & $\frac{T P}{g / L}$ & $\frac{G L O}{g / L}$ & $\frac{\mathrm{BUN}}{\mathrm{mg} / \mathrm{L}}$ \\
\hline Healthy & 2.63 & 0.33 & 106 & 13.9 & 253 & 7.37 & 35.5 & $19.0^{*}$ & 4.81 \\
\hline Ascites & $3.52^{*}$ & $0.44^{*}$ & 145 & $17.4^{*}$ & 275 & $10.3^{*}$ & 32.3 & 16.4 & 5.16 \\
\hline SEM & 0.19 & 0.03 & 8.04 & 0.72 & 21.1 & 0.52 & 1.53 & 0.87 & 0.38 \\
\hline$p$-value & 0.001 & 0.002 & 0.021 & 0.008 & NS & 0.001 & NS & 0.016 & NS \\
\hline
\end{tabular}

RBC: Red blood cells, HCT: Hematocrit, HGB: Haemoglobin,GLU: Glucose,TG: Triglyceride,CHO: Cholesterol, TP: Total protein, GLO:Globulin, BUN: Blood urea nitrogen. 
Table 4 Changes of liver biochemical parameters between ascites and healthy broilers $(n=8)$

\begin{tabular}{|c|c|c|c|c|c|c|c|}
\hline Items & MDA & T-SOD & HK & SDH & PK & $\mathrm{Na}^{+}-\mathrm{K}^{+}$-ATPase & LD \\
\hline & $\overline{\mathrm{nmol} / \mathrm{mg} \text { protein }}$ & $\overline{\mathrm{U} / \mathrm{mg} \text { protein }}$ & $\overline{\mathrm{U} / \mathrm{mg} \text { protein }}$ & $\overline{\mathrm{U} / \mathrm{mg} \text { protein }}$ & $\overline{\mathrm{U} / \mathrm{g} \text { protein }}$ & $\overline{\mu \mathrm{molPi} / \mathrm{mg} \text { protein/h }}$ & $\mathrm{mmol} / \mathrm{mg}$ protein \\
\hline Healthy & 0.27 & $4.63^{*}$ & $65.14^{*}$ & $5.53^{*}$ & 34.9 & 6.29 & 0.20 \\
\hline Ascites & $0.31^{*}$ & 3.74 & 41.35 & 3.99 & 29.8 & 8.01 & $0.16^{*}$ \\
\hline SEM & 0.01 & 0.18 & 4.70 & 0.38 & 1.87 & 0.89 & 0.012 \\
\hline$p$-value & 0.012 & 0.005 & 0.01 & 0.038 & NS & NS & 0.044 \\
\hline
\end{tabular}

MDA: Malondialdehyde, T-SOD: Total superoxide dismutase, HK: Hexokinase, SDH: Succinodehydrogenase, MDH: Malic dehydrogenase, PK: Pyruvate kinase, LD: Lactic acid.

pulmonary hypertension [26]. Hypertrophy of organs was a sign of abnormal function leading to the decrease in growth performance [7]. Results of the present study indicated that liver and heart of ascites broilers was significantly hypertrophic with the lower body weight, which increased the susceptibility to ascites and aggravated the occurrence of ascites syndrome.

\section{Lipid antioxidant capacity and enzymes activity related to} energy metabolism

Oxidative stress was aggravated in ascites broilers [27]. Ascites syndrome induced a large number of reactive oxygen species (ROS) and MDA production in many tissues, causing lipid peroxidation in mitochondrial membrane, leading to over-consumption of antioxidant enzymes and inadequately synthesize. The concentration of free radical and MDA were increased in serum and other tissues, but the activity of SOD and GSH-Px was significantly reduced [28]. The current study indicated that hepatic MDA concentration of ascites broilers was increased, and T-SOD activity was significantly decreased, which indicated that hepatic damage due to lipid peroxidation was significantly aggravated in ascites broilers. The scavenging agents of free radical, such as Vitamin E [29,30], or L-carnitine can enhance the defense function of antioxidative system, and reduce the susceptibility to ascites [28].

Cold temperature can increase ascites susceptibility by increasing both metabolic oxygen requirements and pulmonary hypertension [15]. HK, SDH and PK are the important enzymes in cell glycolysis and Krebs cycle. The activity of these enzymes is of importance to glucose catabolism. $\mathrm{Na}^{+}-\mathrm{K}^{+}$-ATPase activity is an important indicator to measure mitochondria function for energy metabolism, and it has close relationship with the decomposition of ATP. The current study indicated that the activity of liver mitochondria enzymes was significantly decreased, which might block the ATP generation process in liver tissue of ascites broilers, so the energy requirement cannot be fulfilled under a cold environment, which may aggravate the development of ascites.

\section{Differentially expressed proteins indentified from proteomics profile}

18 proteins expression difference were identified between ascites and healthy broilers. These proteins were mainly associated with the following biological processes: 1) cytoskeleton; 2) glucose, lipids and amino acid metabolism; 3) cell secretion; 4) cell apoptosis; 5) signal transduction; 6) immune and inflammatory response;

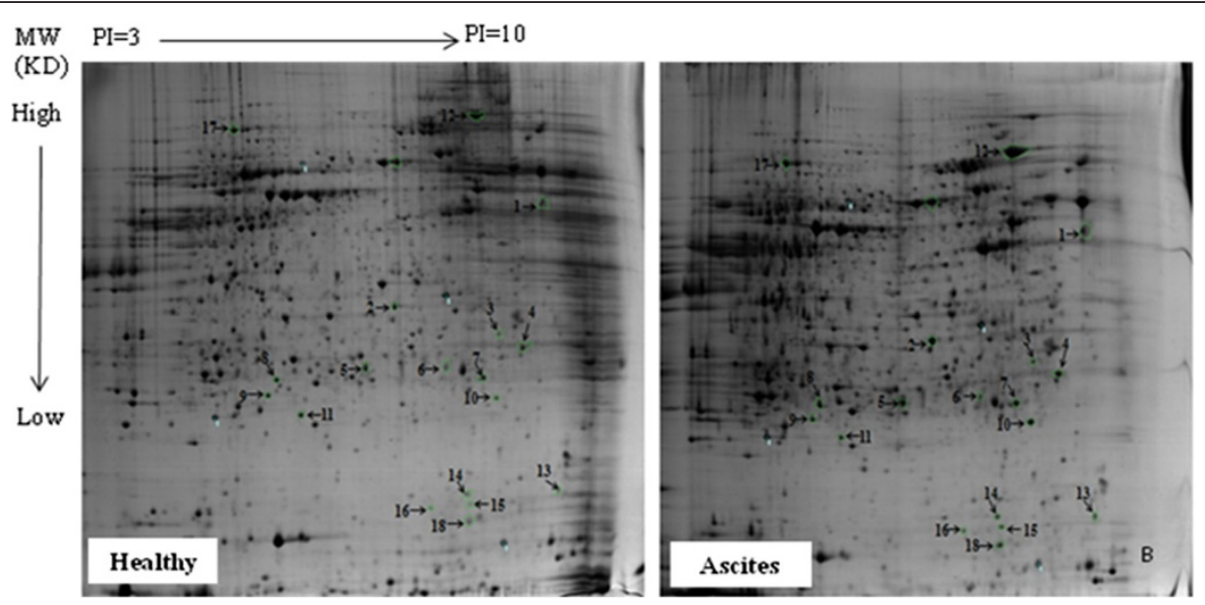

Figure 1 Representative protein expression profiles in the liver of ascites and healthy broilers. 
Table 5 Liver differentially expressed proteins of broilers identified by PMF query

\begin{tabular}{|c|c|c|c|c|c|c|}
\hline Match ID & Score & Name & Id & Mass & $\mathrm{Pi}$ & Coverage (\%) \\
\hline 882 & 89 & similar to keratin 10 isoform 2 & gi|21961605 & 56863 & 5.05 & 22 \\
\hline 520 & 98 & chain A, crystal structures of chicken annexinV in complex with $\mathrm{Ca}^{2+}$ & gi|62738641 & 36159 & 5.61 & 39 \\
\hline 443 & 91 & similar to proteasome subunit alpha type 3 & gi|73963044 & 15430 & 7.77 & 53 \\
\hline 409 & 72 & keratin, type II cytoskeletal 1 & gi|160961491 & 65621 & 7.62 & 20 \\
\hline 333 & 55 & N-ethylmaleimide-sensitive factor & gi|118102799 & 82638 & 6.38 & 18 \\
\hline 311 & 57 & ring finger protein 170 , isoform CRA_b & gi|119583606 & 22591 & 8.6 & 28 \\
\hline 304 & 75 & Rho GDP dissociation inhibitoralpha & gi|224074434 & 23247 & 5.02 & 34 \\
\hline 294 & 117 & dihydropteridinereductase & gi|57529509 & 25107 & 6.43 & 34 \\
\hline 252 & 53 & ryncolin-1 & gi|299791444 & 38896 & 5.42 & 22 \\
\hline 248 & 97 & translationally-controlled tumor protein homolog & gi|45382329 & 19689 & 4.9 & 25 \\
\hline 213 & 110 & similar to natural killer cell enhancing factor isoform 4 & gi|50751518 & 22529 & 8.24 & 53 \\
\hline 1895 & 264 & unnamed protein product & gi|12835845 & 56972 & 5.01 & 37 \\
\hline 144 & 60 & neutrophil cytosol factor 2 variant & gi|62088874 & 68173 & 5.9 & 22 \\
\hline 136 & 60 & glia maturation factor beta & gi|71894963 & 16884 & 5.19 & 54 \\
\hline 130 & 118 & keratin, type II cytoskeletal 1 & gi|160961491 & 65621 & 7.62 & 28 \\
\hline 125 & 49 & serpin B3 & gi|41235787 & 44800 & 8.58 & 25 \\
\hline 1093 & 302 & chain a, the structure of chicken mitochondrial PEPCK. & gi|110591367 & 68010 & 6.55 & 48 \\
\hline 108 & 52 & hypothetical protein LOC100446659 & gi|297668385 & 23305 & 9.12 & 23 \\
\hline
\end{tabular}

and 7) cellular redox homeostasis. However, there are few reports on the relationship between the functions of differentially expressed proteins and ascites syndrome. It is reported that PEPCK, rather than being involved exclusively in gluconeogenesis, has a broader metabolic function in the cataplerosis of citric acid cycle intermediates (removal of citric acid cycle anions), which is required for gluconeogenesis and glyceroneogenesis [31]. So we are very interested in the PEPCK.

It is almost 60 years since the M-PEPCK (EC 4.1.1.32) from chicken liver was first reported by Utter and Kurahashi [32]. Most mammalian species display almost equal activity of the two isoforms of PEPCK in their liver, one in mitochondria (M-PEPCK) and another in cytosol (C-PEPCK), whereas chicken only express the gene for M-PEPCK in their liver (The expression of liver C-PEPCK decreases to negligible levels $2 \mathrm{~d}$ before hatching) [33-35]. In chicken, glucose synthesis in the liver is restricted to the Cori cycle, whereas net gluconeogenesis from amino acids occurs in the kidney, a tissue that contains both isoforms of PEPCK. Thus, birds recycle lactate generated by glycolysis in the muscle and red cells to the liver for gluconeogenesis [33,36]. These differences in the regulation of gluconeogenesis may be related to the different ways of generating cytosolic $\mathrm{NADH}$ when specific metabolic precursors are used in gluconeogenesis [37]. In avian liver, the synthesis of phosphoenolpyruvate is restricted to the mitochondria, so that a continuous supply of NADH from oxidationreduction reactions in the cytosol is needed. In tissues

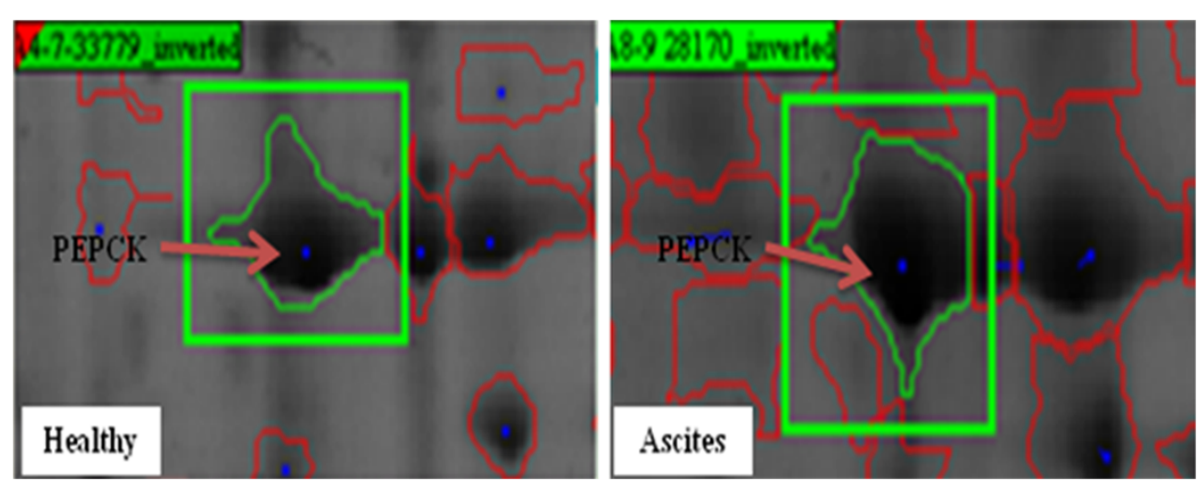

Figure 2 Abundance of differentially expressed PEPCK protein in the livers of ascites and healthy broilers. 


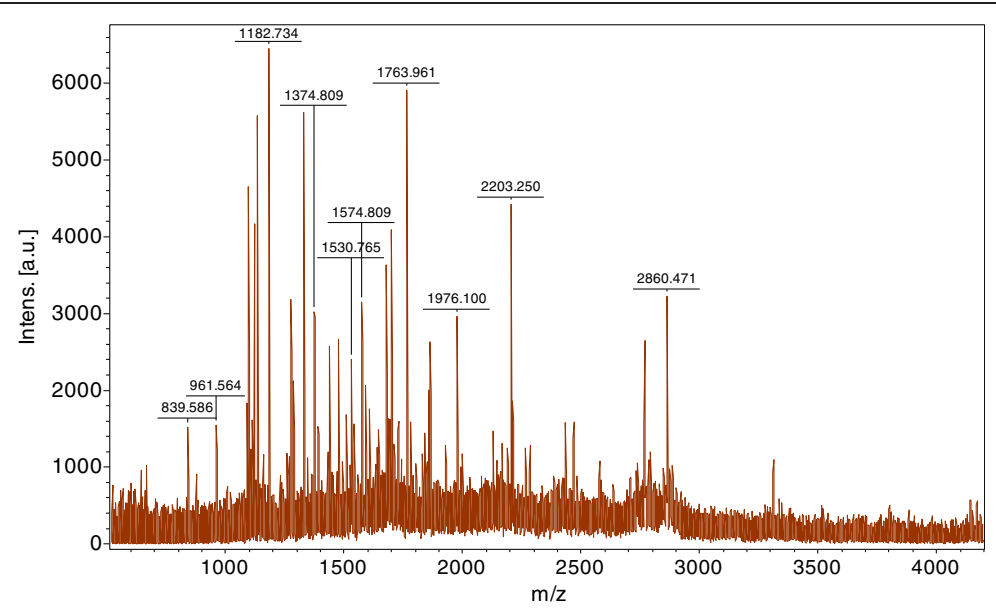

Figure 3 MALDI-TOF mass spectrum of M-PEPCK from a 2D gel.

that possess a C-PEPCK, malate is transported across the mitochondrial membrane, generating $\mathrm{NADH}$ in the cytosol where it is oxidized to oxaloacetate, then a variety of gluconeogenic precursors can be used (alanine, pyruvate and gluconeogenic amino acids) [34].

Daneshyar et al. (2009) reported that fasting blood sugar of cold-temperature treated birds at wks 4 and wks 6 was significantly greater than normal-temperature treated birds, and they attributed it to higher gluconeogenesis level in ascites broilers [16,38]. Besides,
Yersin et al. (1992) and Biswas et al. (1995) observed decreased concentration of serum albumin in ascites broilers. It is suggested that deamidation process might contribute to the high rate of gluconeogenesis in hepatocytes of ascites broilers [17,18]. This study found that serum globulin level was significantly decreased in ascites broilers. In addition, the expression of liver MPEPCK in ascites broilers was significantly up-regulated, with the significant decrease of liver lactic acid level and increase of serum glucose level in ascites broilers.

Table 6 Expression volume of liver different protein spots in 2 DE map

\begin{tabular}{|c|c|c|c|c|}
\hline \multirow{2}{*}{$\begin{array}{l}\text { Spot } \\
\text { No. }\end{array}$} & \multirow[t]{2}{*}{ Protein name } & \multicolumn{2}{|c|}{ Expression volume $^{*}$} & \multirow{2}{*}{$\begin{array}{c}p- \\
\text { value }\end{array}$} \\
\hline & & Healthy & Ascites & \\
\hline 1 & similar to keratin 10 isoform 2 & 0.141 & 0.150 & 0.081 \\
\hline 2 & chain $\mathrm{A}$, crystal structures of chicken annexin $v$ in complex with $\mathrm{Ca}^{2+}$ & 0.042 & 0.057 & 0.076 \\
\hline 3 & similar to proteasome subunit alpha type 3 & 0.053 & 0.063 & 0.120 \\
\hline 4 & keratin, type II cytoskeletal 1 & 0.085 & 0.077 & 0.041 \\
\hline 5 & N-ethylmaleimide-sensitive factor & 0.051 & 0.071 & 0.045 \\
\hline 6 & ring finger protein 170 , isoform CRA_b & 0.088 & 0.049 & 0.004 \\
\hline 7 & Rho GDP dissociation inhibitor (GDI) alpha & 0.120 & 0.156 & 0.002 \\
\hline 8 & dihydropteridinereductase & 0.122 & 0.128 & 0.053 \\
\hline 9 & ryncolin-1 & 0.080 & 0.121 & 0.004 \\
\hline 10 & translationally-controlled tumor protein homolog & 0.131 & 0.160 & 0.014 \\
\hline 11 & similar to natural killer cell enhancing factor isoform 4 & 0.126 & 0.074 & 0.027 \\
\hline 12 & unnamed protein product & 0.214 & 0.228 & 0.109 \\
\hline 13 & neutrophil cytosol factor 2 variant & 0.129 & 0.150 & 0.216 \\
\hline 14 & glia maturation factor beta & 0.046 & 0.046 & 0.039 \\
\hline 15 & keratin, type II cytoskeletal 1 & 0.193 & 0.387 & 0.177 \\
\hline 16 & serpin B3 & 0.171 & 0.231 & 0.057 \\
\hline 17 & chain $A$, the structure of chicken mitochondrial PEPCK. & 0.084 & 0.130 & 0.006 \\
\hline 18 & hypothetical protein LOC100446659 & 0.432 & 0.894 & 0.114 \\
\hline
\end{tabular}

${ }^{*}$ means the volume of protein spot in $2 \mathrm{D}$ gel calculated by imagemaster Platinum Version 7.0 software. 
It is implied that the gluconeogenesis level was increased during the development of broilers ascites under a low ambient temperature.

In summary, the study provides the first evidence for the changes of hepatic proteomics profile between ascites and healthy broilers. Eighteen differentially expressed protein spots were identified between ascites and healthy broilers. It can be concluded that liver oxidation damage and energy generation obstruction occurred in ascites broilers. Hepatic M-PEPCK expression of ascites broilers was significantly increased-indicating that gluconeogenesis level was increased in ascites broilers under low ambient temperature. It is implied that some potential regulatory reagents may reduce ascites susceptibility by increasing gluconeogenesis level through up-regulating M-PEPCK protein expression.

\section{Endnotes}

Data in this paper were partially presented at the 2012 Poultry Science Association Annual Meeting, Athens, Georgia, America (p149).

\section{Competing interests}

The authors declare that they have no competing interests.

\section{Authors' contribution}

All authors read and approved the final manuscript.

\section{Acknowledgements}

This study was financed by Beijing Natural Science Foundation (6111002) and the Ear-marked Fund for China Agriculture Research System. Dong Ning, Yunzhi Peng, Hong Cai, Jianzhuang Tan participated in the analysis of biochemical parameters. We thank Ying Yang and Dan Liu for critical reading of the manuscript. We also thank Professor Jidong Feng and Mr. Jingqiang Zhang from the College of Biological Sciences of China Agriculture University for liver proteomics analysis.

Received: 14 September 2012 Accepted: 3 December 2012 Published: 11 December 2012

\section{References}

1. Balog JM: Ascites syndrome (pulmonary hypertension syndrome) in broiler chickens: are we seeing the light at the end of the tunnel? Avian Poultry Biol Rev 2003, 14:99-126.

2. Julian RJ: Ascites in poultry. Avian Pathol 1993, 22:419-454.

3. Currie RJW: Ascites in poultry: recent investigations. Avian Pathol 1999, 28:313-326

4. Crespo R, Shivaprasad HL: Diseases of poultry. 11th edition. Ames: Lowa State Press; 2003:1072-1075.

5. Moghadam HK, Mcmillan I, Chambers JR, Julian RJ, Tranchant CC: Heritability of sudden death syndrome and its associated correlations to ascites and body weight in broilers. Br Poult Sci 2005, 46:54-57.

6. Baghbanzadeh A, Decuypere E: Ascites syndrome in broilers: physiological and nutritional perspectives. Avian Pathol 2008, 37:117-126.

7. Mohammadpour AA: Comparative histomorphological study of heart in healthy and ascites broiler chickens in Shahrekord district. Iran. Vet Res Commun 2007, 31:461-465.

8. Shlosberg A, Belaiche M, Berman E, Perk S, Deeb N, Neumark E, Cahaner A: Relationship between broiler chicken hematocrit-selected parents and their progeny with regard to hematocrit, mortality from ascites and body weight. Res Vet Sci 1998, 64:105-109.

9. Luger D, Shinder D, Wolfenson D, Yahav S: Erythropoiesis regulation during the development of ascites syndrome in broiler chickens: A possible role of corticosterone. J Anim Sci 2003, 81:784-790.
10. Hamal KR, Wideman RF, Anthony NB, Erf GF: Differential expression of vasoactive mediators in microparticle challenged lungs of chickens that differ in susceptibility to pulmonary arterial hypertension. Am J Physiol Regul Integr Comp Physiol 2009, 298:235-242.

11. Hamal KR, Wideman RF, Anthony NB, Erf GF: Differential gene expression of proinflammatorychemokines and cytokines in lungs of ascitesresistant and-susceptible broiler chickens following intravenous cellulose microparticle injection. Vet Immunol Immunopathol 2010, 133:250-255.

12. Shimomura I, Matsuda M, Hammer RE, Bashmakov Y, Brown MS, Goldstein $\mathrm{J}$ : Decreased IRS-2 and increased SREBP-1c lead to mixed insulin resistance and sensitivity in livers of lipodystrophic and ob/ob mice. Mol Cell 2000, 6:77-86.

13. Spiegelman BM, Flier JS: Obesity and the regulation of energy balance. Cell 2001, 104:531-543.

14. Cisar CR, Balog JM, Anthony NB, Donoghue AM: Differential expression of cardiac muscle mitochondrial matrix proteins in broilers from ascitesresistant and susceptible lines. Poult Sci 2005, 84:704-708.

15. Stolz JL, Rosenbaum LM, Jeong D, Odom TW: Ascites syndrome, mortality and cardiological responses of broiler chickens subjected to cold exposure. Poult Sci 1992, 71(Suppl 1):4.

16. Diaz-Cruz A, Nava C, Villanueva R, Serret M, Guinzberg R, Pina E: Hepatic and cardiac oxidative stress and other metabolic changes in broilers with the ascites syndrome. Poult Sci 1996, 75:900-903.

17. Yersin AG, Huff WE, Kubena LF, Elissalde MA, Harvey RB, Witzel DA, Giroir LE: Changes in hematological, blood gas and serum biochemical variables in broilers during exposure to stimulated high altitude. Avian Disease 1992, 36:189-197.

18. Biswas NK, Dalapati MR, Bhowmik MK: Ascites syndrome in broiler chickens: observations on certain biochemical and pathological changes. Indian J Anim Sci 1995, 65:1068-1072.

19. NRC: Nutrition requirements of poultry. 9th edition. Washington DC: Natl Acad Sci; 1994.

20. Peacock AJ, Pickett CK, Morris KM, Reeves JT: Spontaneous pulmonary hypertension in rapidly growing broiler chickens reared at sea level [abstract]. Am Rev of Respir Dis 1988, 137:s106.

21. Julian RJ, McMillan I, Quinton M: The effect of cold and dietary energy on right ventricular hypertrophy, right ventricular failure and ascites in meat-type chickens. Avian Pathol 1989, 18:675-684.

22. Tan GY, Yang L, Fu YQ, Feng JH, Zhang MH: Effects of different acute high ambient temperatures on function of hepatic mitochondrial respiration, antioxidative enzymes, and oxidative injury in broiler chickens. Poult Sci 2010, 89:115-122.

23. SPSS: SPSS version 16.0 for windows. Illth edition. Chicago: SPSS Inc; 2008.

24. Wideman RF, Forman MF, Hughes JD Jr, Kirby YK, Marson N, Anthony NB: Flow-dependent pulmonary vasodilation during acute unilateral pulmonary artery occlusion in jungle fowl. Poult Sci 1998, 77:615-626.

25. Shlosberg A, Bellaiche M, Zeitlin M, Ya'akobi M, Cahaner A: Haematocrit values and mortality from ascites in cold-stressed broilers from parents selected by haematocrit. Poult Sci 1996, 75:1-5.

26. Zerehdaran S, Grevehof EMV, Waaij EHVD, Bovenhuis H: A bivariate mixture model analysis of body weight and ascites traits in broilers. Poult Sci 2006, 85:32-38.

27. Enkvetchakul B, Bottje W, Anthony N, Moore R, Huff W: Compromised antioxidant status associated with ascites in broilers. Poult Sci 1993, $12: 2272-2280$

28. Geng AL, Guo YM, Yuan JM: Effects of dietary L-carnitine and coenzyme Q10 supplementation on performance and ascites mortality of broilers. Arch Anim Nutr 2004, 58:473-482.

29. Bottje W, Erf G, Bersi T, Wang S, Barnes D, Beers K: Effect of dietary DL-a-tocopherol on tissue and $a$ - and $\gamma$-tocopherol and pulmonary hypertension syndrome (ascites) in broilers. Poult Sci 1997, 75:1507-1512

30. Villar-Patino G, Diaz-Cruz A, Avila-Gonzalez E, Guinzberg R, Pablos JL, Pina E: Effects of dietary supplementation with vitamin $C$ or vitamin $E$ on cardiac lipid peroxidation and growth performance in broilers at risk of developing ascites syndrome. Am J Vet Res 2002, 63:673-676.

31. Hanson RW: Thematic minireview series: a perspective on the biology of phosphoenolpyruvatecarboxykinase 55 years after its discovery. J Biol Chem 2009, 284:27021-27023.

32. Utter MF, Kurahashi K: Mechanism of action of oxalacetic carboxylase from liver. J Am Chem Soc 1953, 75:758. 
33. Soling HD, Kleineke J, Willms B, Janson G, Kuhn A: Relationship between the intracellular distribution of P-enolpyruvatecarboxykinase, the regulation of gluconeogenesis and the energy cost of glucose formation. Eur J Biochem 1973, 37:233-243.

34. Weldon SL, Rando A, Kalonick PA, Matathias A, Hod Y, Savon S, Cook JS, Hanson RW: Nucleotide sequence of the CAMP for the mitochondrial form of P-enolpy-ruvatecarboxykinase (GTP) from the chicken [abstract]. J Cell Biol 1988, 107:412.

35. Savon S, Hakimi P, Hanson RW: Expression of the genes for the mitochondrial and cytosolic forms of PEPCK in avian liver during development. Biol Neonate 1993, 64:62-68.

36. Hanson RW, Garber AJ: P-enolpyruvatecarboxykinase: I. Its role in gluconeogenesis. Am J Clin Nutr 1972, 25:1010-1021.

37. Hod Y, Morris S, Hanson RW: Induction by cAMP of the mRNA encoding the cytosolic form of phosphoenolpyruvatecarboxykinase (GPT) from the chicken. J Biol Chem 1984, 259:15603-15608.

38. Daneshyar M, Kermanshahi H, Golian A: Changes of biochemical parameters and enzyme activities in broiler chickens with cold-induced ascites. Poult Sci 2009, 88:106-110.

doi:10.1186/2049-1891-3-41

Cite this article as: Wang et al:: Changes of hepatic biochemical

parameters and proteomics in broilers with cold-induced ascites. Journal of Animal Science and Biotechnology 2012 3:41.

\section{Submit your next manuscript to BioMed Central and take full advantage of:}

- Convenient online submission

- Thorough peer review

- No space constraints or color figure charges

- Immediate publication on acceptance

- Inclusion in PubMed, CAS, Scopus and Google Scholar

- Research which is freely available for redistribution 